\title{
Cimento de ionômero de vidro e sua aplicabilidade na Odontologia: Uma revisão narrativa com ênfase em suas propriedades
}

Glass ionomer cement and its applicability in Dentistry: A narrative review with emphasis on its properties

El cemento de ionómero de vidrio y su aplicabilidad en odontología: Una revisión narrativa con énfasis en sus propriedades

Recebido: 09/04/2021 | Revisado: 16/04/2021 | Aceito: 19/04/2021 | Publicado: 30/04/2021

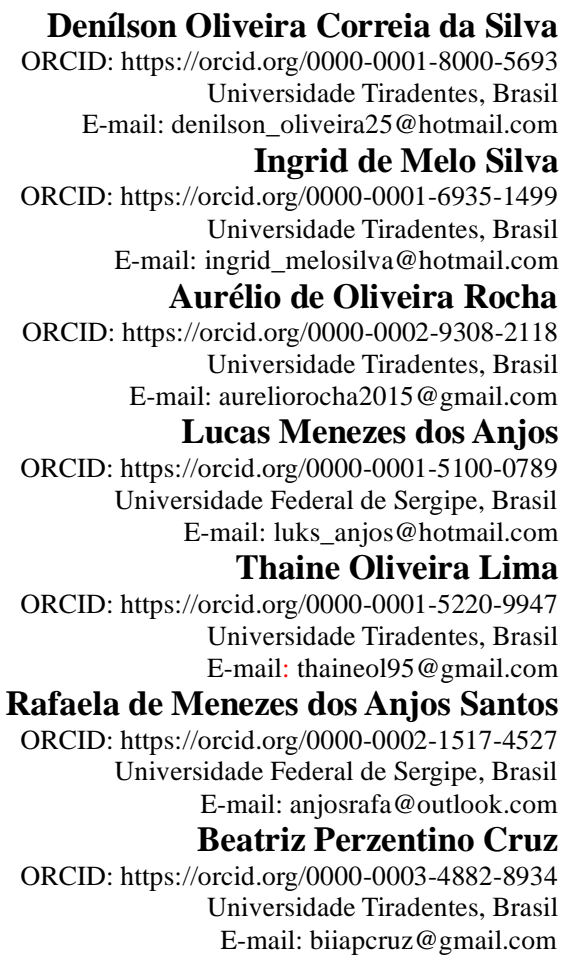

\section{Resumo}

O presente trabalho trata-se de uma revisão narrativa da literatura com o objetivo de discutir acerca das propriedades físicas, mecânicas e biológicas dos cimentos de ionômero de vidro (CIVs). Para reabilitar unidades dentais com cavidades patológias o cirurgião-dentista pode lançar mão de diversos materias, dentre eles podemos destacar os cimentos de ionômero de vidro, sendo esse um dos materiais mais utilizados para reabilitação oral, principalmente na dentição decídua. Sua ampla utilização está associada as excelentes propriedades desse material, como: liberação e absorção de flúor, garantindo redução da progressão e início de lesões cariosas; coeficiente de expansão térmico linear semelhante a estrutura dental, reduzindo draticamente os casos de infiltração marginal; adesividade nos tecidos; biocompatibilidade, para assim não agredir os tecidos biológicos do dente; resistência e estética aceitáveis, quando comparado a outros materiais como óxido de zinco e eugenol . Para realização desse estudo foi realizada uma busca completa nas bases de dados: PubMed, Scielo, Lilacs e Google Scholar, utilizando as palavras-chave "glass ionomer cements, dental materials and dentistry", inseridas nas buscas de maneira cruzada adotando a expressão boolena "and". Afim de selecionar os artigos a serem analisados foram elencados critérios de inclusão e exclusão. Para garantir sucesso restaurador e longevidade das restaurações com ionômero o profissional necessita realizar um diagnóstico e técnica correta, para que dessa forma haja um melhor aproveitamento e desempenho das propriedades desse material. Palavras-chave: Cimentos de ionômero de vidro; Materiais dentários; Odontologia.

\footnotetext{
Abstract

The present work is a narrative review of the literature to discuss the physical, mechanical, and biological properties of glass ionomer cement (CIVs). To rehabilitate dental units with pathological cavities, the dentist can use several
} 
materials to highlight glass ionomer cement, one of the most used oral rehabilitation materials, especially in the primary dentition. Its wide use is associated with the excellent properties of this material, such as fluoride release and absorption, ensuring reduced progression and onset of carious lesions; coefficient of linear thermal expansion similar to the dental structure, drastically reducing the cases of marginal infiltration; adhesiveness in tissues; biocompatibility, so as not to harm the biological tissues of the tooth; acceptable strength and aesthetics when compared to other materials such as zinc oxide and eugenol. To carry out this study, a complete search was carried out in the databases: PubMed, Scielo, Lilacs and Google Scholar, using the keywords "glass ionomer cement, dental materials and dentistry", inserted in the searches in a cross way adopting the expression boolean " and ". In order to select the articles to be analyzed, inclusion and exclusion criteria were listed. To ensure restorative success and longevity of ionomer restorations, the professional needs to perform a correct diagnosis and technique so that there is a better use and performance of the properties of that material.

Keywords: Glass ionomer cements; Dental materials; Dentistry.

\section{Resumen}

El presente trabajo es una revisión narrativa de la literatura con el fin de discutir sobre las propiedades físicas, mecánicas y biológicas de los cementos de ionómero de vidrio (CIV). Para rehabilitar unidades dentales con caries patológicas, el odontólogo puede utilizar varios materiales, entre los que podemos destacar los cementos de ionómero de vidrio, que es uno de los materiales más utilizados para la rehabilitación oral, especialmente en dentición temporal. Su amplio uso está asociado a las excelentes propiedades de este material, tales como: liberación y absorción de flúor, asegurando una reducción de la progresión y aparición de las lesiones cariosas; coeficiente de expansión térmica lineal similar a la estructura dentaria, reduciendo drásticamente los casos de infiltración marginal; adhesividad en tejidos; biocompatibilidad, para no dañar los tejidos biológicos del diente; resistencia y estética aceptables en comparación con otros materiales como el óxido de zinc y el eugenol. Para la realización de este estudio se realizó una búsqueda completa en las bases de datos: PubMed, Scielo, Lilacs y Google Scholar, utilizando las palabras clave "cementos de ionómero de vidrio, materiales dentales y odontología", insertadas en las búsquedas de forma transversal adoptando la expresión booleano "y". Para seleccionar los artículos a analizar se enumeraron los criterios de inclusión y exclusión. Para asegurar el éxito restaurativo y la longevidad de las restauraciones de ionómero, el profesional debe realizar un correcto diagnóstico y técnica, para que haya un mejor uso y rendimiento de las propiedades de ese material.

Palabras clave: Cementos de ionómero de vidrio; Materiales dentales; Odontología.

\section{Introdução}

$\mathrm{Na}$ prática clínica odontológica, os materiais restauradores são amplamente utilizados com o intuito de manter e devolver a forma, função e estética da estrutura dentária afetada por lesões de cárie tanto na dentição decídua como na permanente. Dessa forma, há um interesse crescente em materiais restauradores com propriedades capazes de proporcionar desempenho funcional e estético, associados a odontologia minimamente invasiva (Almeida et al, 2017).

A odontologia minimamente invasiva tem por intuito propiciar meios para a remineralização do tecido dentário lesionado por cárie, através da utilização de materiais odontológicos com excelentes propriedades, impedindo a progressão de lesões iniciais e, consequentemente, preconizando a promoção da manutenção e longevidade da estrutura dental sadia (Becci et al, 2017).

Em função disso, o cimento de ionômero de vidro (CIV) têm sido utilizado constantemente no âmbito odontológico devido às suas vantajosas propriedades clínicas (Spezzia, 2017). Trata-se de um material híbrido constituído de partículas inorgânicas de vidro disseminadas em uma matriz insolúvel de hidrogel, sendo desenvolvido no ano de 1972 por Wilson e Kent, tendo por objetivo propiciar a evolução do cimento de silicato e cimento de policarboxilato um material restaurador com propriedades semelhantes (Muniz et al, 2020).

Os CIVs são aplicados na odontologia em procedimentos preventivos e curativos como: tratamento restaurador atraumático, restaurações de lesões cariosas, selamento de fóssulas e fissuras, forramento e bases de cavidades, cimentação de pinos, assim como na fixação de braquetes ortodônticos (Nicholson et al, 2020; Coelho et al, 2020). São comumente apresentados como uma solução aquosa de ácido poliacrílico e um pó de vidro finamente dividido, que são misturados por um método apropriado para formar uma pasta viscosa que endurece rapidamente (Spezzia, 2017). 
É importante que ao selecionar um determinado material, faz-se necessário observar suas propriedades (Poornima et al, 2019). Dessa forma, dentre as propriedades referentes ao CIV, destacam-se a adesão aos tecidos mineralizados, resistência mecânica, estética aceitável, coeficiente de expansão térmica linear semelhante a estrutura dental, bioatividade, biocompatibilidade e liberação de flúor, outorgando, assim, importantes características preventivas e reabilitadoras ao dente (Nicholson et al, 2020). Vale ressaltar que a adesão a estrutura dental juntamente com a liberação de flúor auxilia na inibição do metabolismo de microrganismos acidogênicos, reduzindo a velocidade de progressão das lesões de cárie (Muniz et al, 2020).

A dosagem do material, a manipulação, bem como a inserção e proteção superficial do material, devem ser seguidas de acordo com as instruções dos fabricantes, sendo de total importância para a obtenção de melhores resultados em suas propriedades, minimizando o risco de propriedades desfavoráveis por meio da sinérese (perda de água) e embebição (ganho de água), que podem resultar em alterações dimensionais, perda das propriedades mecânicas e formação de trincas e rachaduras (Marakby et al, 2017; Nicholson et al, 2020). Portanto, a proteção da superfície, após a presa inicial do material, é de fundamental importância, sendo, para isso, utilizados vernizes do próprio cimento, vernizes cavitários, sistemas adesivos, vaselina, resina fluida ou esmalte cosmético (Ferreira et al, 2018).

Os CIVs podem ser classificados de acordo com à sua natureza ou mesmo quanto à sua aplicação (Tagliaferro et al, 2017). Quanto à sua natureza, os CIVs podem ser convencionais, quando compostos por um pó de partículas de vidro e um líquido poliacrílico; reforçados por metais, se ao pó convencional forem adicionadas partículas de liga de amálgama ou de prata; e modificados com resina, quando parte do líquido convencional é substituído por monómero de resina ou metacrilato, geralmente o hidroxietil metacrilato (HEMA) (Dornellas et al, 2018).

Por outro lado, quanto à sua aplicação, os CIVs dividem-se em quatro tipos. No tipo I, incluem-se os cimentos para coroas e dispositivos ortodônticos (Dornellas et al, 2018). O tipo II, ou CIV de elevada viscosidade, são ionómeros de vidro usados em restaurações, ao passo que o tipo III, ou CIV de baixa viscosidade, é o usado como base e inicialmente usado como selante. Por fim, o tipo IV contempla os CIVs modificados com resina (Souza et al, 2018).

O cimento de ionômero de vidro convencional apresenta-se como um material restaurador autopolimerizável, com propriedades como, liberação de fluoretos e biocompatibilidade com a estrutura dentária (Dornellas et al, 2018). Contudo, exibe baixa tenacidade à fratura, com menor resistência ao desgaste, limitando-se o seu uso em áreas com poucas tensões mastigatórias (Oliveira et al, 2019). Neste contexto, a fim de aprimorar tais propriedades, foram desenvolvidos os cimentos de ionômero de vidro modificado por resina, que possui as mesmas aplicações clínicas que os ionômeros de vidro convencionais, porém proporciona uma melhor estética, sendo fotopolimerizável e livres de bolhas, uma vez que não requer a manipulação do material (Machado et al, 2019; Nicholson et al, 2020).

Com a evolução dos materiais restauradores e conhecimento de técnicas reabilitadoras associadas houve um aumento significativo nos procedimentos clínicos vinculados ao reparo dental (Poornima et al, 2019). Em contrapartida, as taxas de insucesso clínico com a utilização dos cimentos ionoméricos ainda mostram taxas expressivas, reflexo da falta de conhecimento sobre sua correta manipulação, indicação e aplicação, interferindo diretamente em suas propriedades (Oliveira et al, 2019; Nicholson et al, 2020). Os profissionais da área odontológica devem buscar conhecimento e atualizações acerca de materiais evidenciando suas propriedades e técnicas científicas preconizadas (Mesquita et al, 2020).

Dessa forma, esse estudo tem por objetivo avaliar, por meio de uma revisão narrativa de estudos recentes, as principais características vinculadas as propriedades físicas, mecânicas e biológicas do cimento de ionômero de vidro. 


\section{Metodologia}

Realizou-se uma revisão narrativa, qualitativa, de cunho descritivo por meio de pesquisa bibliográfica exploratória, nas bases de dados PubMed (www.pubmed.com), Scielo (www.scielo.com), GoogleScholar (scolar.google.com.br) e Lilacs (www.lilacs.com). A pesquisa foi realizada no mês de agosto de 2020, utilizando os descritores (glass ionomer cements, dental materials and dentistry) os quais foram inseridos na plataforma de maneira cruzada adotando a expressão booleana "AND" (inserção de duas ou mais palavras). Após a seleção dos artigos, de acordo com os critérios de inclusão e exclusão descritos na Tabela 1, os mesmos foram fichados e tabulados.

Tabela 1- Tabela com os critérios de inclusão e exclusão elencados para seleção dos artigos.

\begin{tabular}{|c|c|c|c|c|}
\hline $\begin{array}{l}\text { CRITÉRIOS } \\
\text { INCLUSÃO. }\end{array}$ & DE & $\begin{array}{l}\text { Artigos científicos } \\
\text { publicados em revistas } \\
\text { nacionais ou internacionais, } \\
\text { que abrangessem os } \\
\text { descritores propostos. }\end{array}$ & $\begin{array}{l}\text { Período: agosto de } 2015 \text { a } \\
\text { agosto de } 2020 \text {. }\end{array}$ & $\begin{array}{l}\text { Idiomas: Inglês, espanhol e } \\
\text { português }\end{array}$ \\
\hline $\begin{array}{l}\text { CRITÉRIOS } \\
\text { EXCLUSÃO. }\end{array}$ & DE & $\begin{array}{l}\text { Revisão de literatura que } \\
\text { não tratasse do objetivo } \\
\text { proposto }\end{array}$ & Texto: não disponível & Outros Idiomas \\
\hline
\end{tabular}

Fonte: Autores.

\section{Resultados e Discussão}

Atualmente na odontologia os cimentos de ionômero de vidro são amplamente aplicados devido à busca de materiais restauradores que possuam características e propriedades amplificadas e aprovadas para o uso clínico, tais como: propriedades de resistência mecânica às manifestações física do meio bucal, liberação de flúor, biocompatibilidade, adesão aos tecidos mineralizados, características estéticas e coeficiente de expansão térmica linear semelhante à estrutura dental (Spezzia , 2017; Abrams et al, 2018).

O CIV encontra-se em crescente aplicação na clínica odontológica, podendo apresentar-se em tipos diferentes, sendo os mais utilizados: o cimento de ionômero de vidro convencional (CIVC) ou autopolimerizável e cimento de ionômero de vidro modificado por resina (CIVMR) ou fotopolimerizáve (Bahsi et al, 2019). O CIVC é formado por pequenas partículas de alumínio -silicato de cálcio-, preparado pela fusão de misturas de sílica, alumínio criolite, fluoretos, fluoretos de alumínio e fosfato de alumínio; já o CIVMR apresenta na sua composição uma mistura de água/HEMA (hidroxietil metacrilato), dimetilacrilato de etilenoglicol (EGDMA) e dimetacrilato de trietilenoglicol (TEGDMA) (Nicholson et al, 2020). Mesmo diante da diferença em sua composição os CIVs apresentam propriedades físicas e químicas semelhantes (Mesquita et al, 2020).

\section{Liberação de Flúor}

Uma das principais propriedades dos cimentos de ionômero de vidro corresponde à absorção e liberação de flúor no meio bucal (Martins et al, 2020). Um estudo realizado em 2013 por Upadhyay et al., indicou que todos os cimentos de ionômero de vidro avaliados liberaram taxas mensuráveis de flúor, sendo mais altas no primeiro dia, seguida por uma queda acentuada no segundo dia, e diminuiu gradualmente ao longo de 3 semanas para uma liberação de baixo nível e de longo prazo, ocasionando assim o efeito de explosão, sendo esse importante para a remineralização, bem como para a redução da viabilidade de bactérias que podem ter permanecido na dentina cariada. Diante disso, vale ressaltar que a liberação de flúor é 
um processo complexo e a quantidade liberada depende de vários fatores intrínsecos que podem afetar a sua liberação, como a formulação, solubilidade ou porosidade do material (Muniz et al, 2020).

Além disso, estudos recentes têm mostrado a capacidade dos cimentos de ionômeros de vidro de adquirir flúor de distintas fontes e funcionar como verdadeiro reservatório desse elemento, permitindo sua liberação constante e mantendo ao longo prazo suas propriedades anticariogênicas (Boaventura et al, 2017). Vários estudos têm mostrado que a liberação de flúor ocorre tanto com os cimentos de ionômeros de vidro convencionais como com os ionômeros modificados por resinas. Porém, o convencional apresenta maior liberação de flúor do que o modificado por resina (Oliveira et al, 2019).

\section{Bioatividade}

Os CIVs têm a capacidade de absorver íons, como os íons cálcio e fosfato, presentes na saliva. Tal fato faz com que desenvolvam uma superfície mais dura, tornando assim o material mais resistente as forças exercidas em sua superfície (Borges et al, 2017).

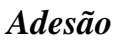

Outra propriedade muito importante dos CIVs é a adesão desse material aos tecidos mineralizados, uma vez que à adesão dos ionômeros de vidro à superfície do dente é uma importante vantagem clínica (Boaventura et al, 2017). Os ionômeros de vidro são preparados a partir de polímeros (ácido acrílico), e sabe-se que esta substância promove adesão, devido a propriedade do cimento de policarboxilato de zinco (Carvalho et al, 2017). A vantagem conferida por sua adesão foi explorada há muitos anos, quando foram propostos ionômeros de vidro para o reparo de lesões de erosão cervical e como selantes de fossas e fissuras (Borges et al, 2017).

A adesão ocorre em várias etapas: primeiro, a aplicação da pasta de cimento fresco permite que ocorra um umedecimento adequado da superfície do dente. Isso é motivado pela natureza hidrofílica do cimento e do dente (Spezzia, 2017). A adesão se desenvolve rapidamente, devido à formação de ligações de hidrogênio entre os grupos carboxila livres do cimento e a água ligada na superfície do dente (Souza et al, 2020). Essas ligações de hidrogênio são lentamente substituídas por verdadeiras ligações iônicas formadas entre cátions no dente e grupos funcionais aniônicos no cimento, o que resulta na formação lenta de uma camada de troca iônica entre o dente e o cimento (Souza et at, 2020). Existe também a possibilidade de fortes ligações entre os grupos carboxilato do ácido poliacrílico e a superfície dental (Marques et al, 2021).

Entretanto, estudos mostram que a falha de um cimento de ionômero de vidro é geralmente coesa, ou seja, ocorre dentro do cimento, e não na interface (Silva et al, 2021). Como resultado, os valores de ligação obtidos em experimentos não são, na verdade, medidas da resistência adesiva, mas da resistência à tração do cimento. Essa força é relativamente baixa em amostras recém-preparadas, mas aumenta à medida que os cimentos amadurecem (Almeida et al, 2017).

\section{Biocompatibilidade}

O termo biocompatibilidade é definido como a habilidade de um material exercer sua função, proporcionando uma boa resposta do hospedeiro (Silva et al, 2021). Esta definição está inserida no conceito de biofuncionalidade e não é uma propriedade única, mas um conjunto de processos que ocorrem através da interação dos tecidos com o material artificial (Ferreira et al, 2018).

Os cimentos de ionômero de vidro são naturalmente biocompatíveis, em parte porque liberam íons ativos (fluoreto, sódio, fosfato e silicato) no meio aquoso circundante a níveis nos quais são biologicamente benéficos (Dornellas et al, 2018). Em condições ácidas, esses íons são liberados em quantidades maiores do que em condições neutras (Dornellas et al, 2018). Além disso, também é liberado cálcio que ocorrem em compostos relativamente insolúveis em soluções neutras (Freitas et al, 
2017). Os íons liberados têm uma variedade de papéis biológicos (Ferreira et al, 2018). O fosfato ocorre na saliva e em equilíbrio com a fase mineral do dente (Lopes et al, 2018). O silicato pode ser incorporado na hidroxiapatita do dente sem afetar adversamente a geometria do cristal, embora não seja claro se isso pode ser feito com a fase mineral dos dentes em condições clínicas (Muniz et al, 2020). O cálcio é um elemento mineral essencial, com muitos usos biológicos (Hasani et al, 2019).

Os ionômeros de vidro também são capazes de absorver íons (Ferreira et al, 2018). Na saliva natural, os cimentos absorvem íons cálcio e fosfato e desenvolvem uma superfície muito mais dura (Machado et al, 2019). Relacionado a isso, observa-se que, quando usados como selantes preventivos, os CIVs formam uma substância profunda dentro da fissura que possui um conteúdo aumentado de cálcio e fosfato e é muito mais resistente que a estrutura original do dente (Spezzia, 2017).

\section{Vedamento Marginal}

Estudos demostram que os cimentos de ionômero de vidro apresentam os coeficientes de expansão térmica mais próxima aos da estrutura dentária (Ferreira et al., 2018). Os ionômeros convencionais possuem um coeficiente de expansão térmica linear melhor do que dos ionômeros modificados por resina, que mostram valores semelhantes aos do amálgama ou das resinas compostas híbridas (Oliveira at al, 2019).

\section{Estética e Resistência}

Com o tempo e o surgimento dos cimentos de ionômero de vidro modificados por resina as propriedades estéticas e características anatômicas dos materiais compósitos de resina dentária foram radicalmente melhoradas devido à incorporação de nanopartículas de vidro ou cerâmica, que facilitam o polimento da superfície desses materiais e proporcionam um maior índice de refletância o que não era possível de ser realizado com os cimentos de ionômero de vidro convencional (Muniz et al, 2020).

Os cimentos de ionômero de vidro modificados por resina sofreram alterações através da incorporação de componentes que polimerizam pela ação da luz e alguns componentes adicionais autopolimerizáveis (Fúcio et al, 2016). Estas modificações fizeram com que o material aumentasse sua resistência ao contato com a umidade e desidratação sofridas precocemente, melhorando também suas propriedades mecânicas e conferindo-lhes maior resistência, estabilidade de cor e durabilidade (Dornellas et al, 2018).

Embora a degradação puramente mecânica (abrasão) produzida pela escovação dos dentes simule o desgaste da superfície das nanopartícuas do CIVMR em um grau significativamente menor em comparação com os CIVCs, estudos in vitro sugerem que não há diferença estatística entre a rugosidade e dureza da superfície dos CIVMRs nanoparticulados e os convencionais, após degradação bacteriana e química (Oliveira et al, 2017). No entanto, até o momento, estudos estabeleceram que, independentemente do tamanho do vidro presente nos CIVC, sua rugosidade e dureza superficial permanecem significativamente menores do que as dos compósitos de resina após degradação bacteriana, mecânica e química devido à menor resistência ao desgaste e maior solubilidade dos primeiros (Punnathara et al, 2017). Portanto, pode-se concluir que os CIVMRs nanoparticulados disponíveis comercialmente não possuem nenhuma vantagem ou desvantagem substancial, em termos de propriedades mecânicas da superfície, em comparação com os materiais restauradores convencionais (Tagliaferro et al, 2017).

\section{Limitações}

Os cimentos convencionais apresentam algumas limitações mecânicas e clínicas, tais como o tempo de reação de geleificação prolongado, sensibilidade, desidratação ou excesso de umidade inicial, baixa resistência à tração e compressão e 
problemas estéticos devido a sua translucidez limitada (Muniz et al, 2020). Os CIVs são preferencialmente aplicados como materiais restauradores de dentes decíduos na odontopediatria e como materiais cimentantes e de forramento em dentes permanentes (Marakby et al, 2017). Estas aplicações estão relacionadas com algumas propriedades físicas dos dentes decíduos, como seu menor valor de dureza e menor força de mordida quando comprada a mordida de adultos, o que gera diferenças na quantidade de desgaste entre dentes decíduos e permanentes (Spezzia, 2017). O uso efetivo dos cimentos de ionômero de vidro depende do controle das suas limitações, bem como da correta manipulação e esmero técnico profissional (Lopes et al, 2019).

\section{Considerações Finais}

A correta manipulação, indicação e aplicação dos materiais restauradores estão intrinsecamente relacionadas com o desempenho clínico apropriado e suas propierdades. Desta maneira, os conhecimentos acerca das particularidades dos cimentos ionoméricos devem ser respeitados, garantindo, assim, que sua utilização basei-se em protocolos clínicos corretos e efetivos.

Assim, em decorrência da constante evolução dos materiais odontológicos, sugere-se o ampliamento de mais pesquisas que ajudem a sondar as limitações do cimento de ionômero de vidro, visando proporcionar melhorias em sua composição.

\section{Referências}

Abrams, T., Abrams, S., Sivagurunathan, K., Moravan, V., Hellen, W., Elman, G., \& Mandelis, A. (2018). Detection of caries around resin-modified glass ionomer and compomer restorations using four different modalities in vitro. Dentistry journal, 6(3), 47.

Almeida, J. R. M. D., Medeiros, T. C. D., Araújo, D. F. G. D., Caldas, S. G. F. R., \& Galvão, M. R. (2017). Avaliação de rugosidade, dureza e superfície dos cimentos de ionômero de vidro após diferentes sistemas de acabamento e polimento. Revista de Odontologia da UNESP, 46(6), $330-335$.

Bahsi, E., Sagmak, S., Dayi, B., Cellik, O., \& Akkus, Z. (2019). The evaluation of microleakage and fluoride release of different types of glass ionomer cements. Nigerian journal of clinical practice, 22(7), 961.

Becci, A. C. D. O., Benetti, M. D. S., Domingues, N. B., \& Giro, E. M. A. (2017). Resistência de união de uma resina composta a cimentos de ionômeros de vidro utilizando diferentes sistemas adesivos. Revista de Odontologia da UNESP, 46(4), 214-219.

Boaventura, J. M. C., Roberto, A. R., de Oliveira Becci, A. C., Ribeiro, B. C. I., de Oliveira, M. R. B., \& de Andrade, M. F. (2017). Importância da biocompatibilidade de novos materiais: revisão para o cimento de ionômero de vidro. Revista de Odontologia da Universidade Cidade de São Paulo, 24(1), $42-50$.

Borges, S., Oliveira, A., Góes, R., Nascimento, F., Silva, C., Santos-Filho, P., \& Martins, V. (2017). Material Restaurador Utilizado Nas Unidades Básicas De Saúde De Um Município De Pequeno Porte Na Região Alto Paranaíba Do Estado De Minas Gerais. Psicologia e Saúde em debate, $3(1), 22-33$.

Carvalho, A. G. L., Barros, S. L. V., Lima, L. M. S., Brandim, A. D. S., Lima, M. D. M., \& Gonçalves, A. R. (2017). Resistência à flexão de cimentos de ionômero de vidro utilizados em tratamento restaurador atraumático com alteração na proporção pó/líquido. ROBRAC, 57-61.

Coelho, C. S., Fedechen, M. C., Volpini, R. M. C., Pedron, I. G., Kubo, H., Friggi, M. N. P., Shitsuka, C. (2020). Evolução da técnica odontológica do tratamento restaurador atraumático. Research, Society and Development. 9 (3).

Dornellas, A. P., Cavalcante, K. D. T., Tedesco, T. K., Floriano, I., \& Imparato, J. C. P. (2018). Molar decíduo infraocluido: Relato de um caso restaurado com cimento ionômero de vidro encapsulado, um ano de acompanhamento. Acta Biomedica Brasiliensia, 9(2), 124-129.

Ferreira, M. S., de Almeida Pereira, N. G., da Silva, C. M., \& Lopes, A. M. S. (2018). Avaliação dos agentes protetores para restaurações com cimento de ionômero de vidro. Clínica e Pesquisa em Odontologia-UNITAU, 9(1), 25-9.

Freitas, M. C. C. D. A., Fagundes, T. C., Modena, K. C. D. S., Cardia, G. S., \& Navarro, M. F. D. L. (2018). Randomized clinical trial of encapsulated and hand-mixed glass-ionomer ART restorations: one-year follow-up. Journal of Applied Oral Science, 26.

Fúcio, S. B., Paula, A. B. D., Sardi, J. C., Duque, C., Correr-Sobrinho, L., \& Puppin-Rontani, R. M. (2016). Streptococcus mutans biofilm influences on the antimicrobial properties of glass ionomer cements. Brazilian dental journal, 27(6), 681-687.

Hasani, Z., Khodadadi, E., Ezoji, F., \& Khafri, S. (2019). Effect of Mechanical Load Cycling on Microleakage of Restorative Glass Ionomers Compared to Flowable Composite Resin in Class V Cavities. Frontiers in dentistry, 16(2), 136.

Lopes, C. M. C. D. F., Galvan, J., Chibinski, A. C. R., \& Wambier, D. S. (2018). Liberação de flúor e rugosidade superficial de um novo cimento de ionômero de vidro: glass carbomer. Revista de Odontologia da UNESP, 47(1), 1-6. 
Machado, K. D. D. S., Reges, R. V., Botelho, T. D. L., \& Dos Santos, F. G. (2019). Efeito da Manipulação e Proporção Pó e Líquido do Cimento de Ionômero de Vidro Reforçado com Zinco na Rugosidade Superficial Parte 1. Revista Ciências e Odontologia, 3(1), $20-24$.

Marakby AME, Alfawaz SA, Alanazi SA, Alduaiji KTA. (2017) Evaluation of Anti-Cariogenic Properties among Four Types of Glass Ionomer Cements. Journal of Oral Dental Health, 1(1):1-5.

Marques, B. B. F., Cabral-Oliveira, G. G., Monnerat, A. F., \& Brito, F. (2021). Uso do Cimento de Ionômero de Vidro de Alta Viscosidade Como Material Restaurador em Pacientes Portadores da Síndrome de Sjögren: Um Relato de Caso. Revista Brasileira de Odontologia, 78, 1-5.

Mesquita, D. C. M., Reges, R. V., da Cruz Peres, L. E., Pereira, C. M., Alves, D. R. S., de Carvalho, R. M., \& dos Santos, F. G. (2020). Perfilometria dimensional do cimento de ionômero de vidro frente aos diferentes ph e tempos de armazenamento. Revista Ciências e Odontologia, 4(2), 44-50.

Muniz, A. B., Bessa, E. R. L., de Holanda, M. A. R., Damasceno, A. G. R. L., de Souza Júnior, P. R. P., da Silva Melo, É. C., \& Beiruth, C. P. (2020). Cimento de ionômero de vidro em odontopediatria: revisão narrativa. Revista Eletrônica Acervo Saúde, 12(10), e3853-e3853.

Nicholson, J. W., Sidhu, S. K., \& Czarnecka, B. (2020). Enhancing the mechanical properties of glass-ionomer dental cements: a review. Materials, 13(11), 2510 .

de Oliveira, E. L., Cabral, G. M. P., de Vasconcelos, R. M. P., Ramalho, R. N., \& Dantas, M. A. P. D. (2018). Avaliação Microbiológica Da Saliva De Crianças Após Adequação Do Meio Bucal Com Cimento Ionômero De Vidro. Revista Campo do Saber, 3(2).

Oliveira, G. L., Carvalho, C. N., Carvalho, E. M., Bauer, J., \& Leal, A. M. A. (2019). The influence of mixing methods on the compressive strength and fluoride release of conventional and resin-modified glass ionomer cements. International journal of dentistry, 2019.

de Oliveira, T. M., Reges, R. R. V., Campos, B. B., de Lucena Botelho, T., \& dos Santos, F. G. (2019). Avaliação Da Alteração Dimensional Do Cimento De Ionômero De Vidro Convencional Utilizando Diferentes Tipos De Proporções Pó/Líquido. Parte II. Revista Ciências e Odontologia, 3(2), 35-42.

Punnathara, S., Krishnakumar, R., Govindarajan, M., Kanaran, M., Philip, S. T., Nair, A. S., \& Peter, J. (2017). A Comparative evaluation of the influence of command set methods on microleakage of glass ionomer cement: An in vitro study. Journal of clinical and diagnostic research: JCDR, 11(6), ZC12.

Souza, A. L. M. D., Magalhães, T. C., Lopes, A. G., Carlo, H. L., Santos, R. L. D., \& Carlo, F. G. D. C. (2018). Qual material possui maior longevidade em molares decíduos: resina composta ou cimento de ionômero de vidro?-revisão sistemática da literatura. HU rev, 115-122.

Souza, M. R. P., de Souza, C. L. S., \& Lima, T. M. (2020). O uso dos diferentes tipos de cimentos de ionômero de vidro restauradores utilizados na prática clínica em cavidades classe v: revisão de literatura. Brazilian Journal of Development, 6(12), 97628-97641.

Silva, W. H., de Jesus Batista, R., Junior, M. F. S., Daroz, L. G. D., \& dos Santos Daroz, C. B. (2021). Avaliação do cimento resinoso autoadesivo como tampão cervical para clareamento interno. Arquivos em Odontologia, 57, 8-16.

Spezzia, S. (2017). Cimento de ionômero de vidro: revisão de literatura. Journal of Oral Investigations, 6(2), 74-88.

Tagliaferro, E. P. D. S., Pardi, V., Ambrosano, G. M. B., Meneghim, M. D. C., Paschoal, M. A. B., Cordeiro, R. D. C. L., \& Pereira, A. C. (2017). Influência do risco de cárie na retenção de um ionômero de vidro modificado por resina usado como selante oclusal: ensaio clínico. Revista de Odontologia da UNESP, 46(4), 208-213. 